Acta vet. scand. 1988, 29, 109-116.

From the Department of Surgery, Faculty of Veterinary Medicine, Swedish University of Agricultural

Sciences, Uppsala, Sweden.

\title{
Cardiovascular and Pulmonary Effects of a New Sedative/Analgesic (Medetomidine) as a Preanaesthetic Drug in the Dog
}

\author{
By Karin Bergström
}

\begin{abstract}
Bergström, K.: Cardiovascular and pulmonary effects of a new sedative/analgesic (Medetomidine) as a preanaesthetic drug in the dog. Acta vet. scand. 1988, 29, 109-116. - Cardiovascular and pulmonary effects of a new sedative/analgesic (medetomidine) as a preanaesthetic drug in the dog. A study was carried out to investigate the possible usefulness of medetomidine (Farmos Group, Turku, Finland) for premedication prior to general anaesthesia with thiopental sodium and halothane. The main emphasis was laid on the circulatory and respiratory effects of medetomidine. Dogs treated with xylazine $(2 \mathrm{mg} / \mathrm{kg}$ ) or placebo (physiological saline solution) served as controls. Medetomidine caused a decrease in blood pressure, heart rate and respiratory rate at all dose levels tested. These decreases were essentially dose -dependent, but there were great individual variations.

It is concluded that the drug can be useful for premedication at the lowest dose level tested $(10 \mu / \mathrm{kg})$. The sedative effect, however, is so strong that an even lower dose might be sufficient for the present purpose.
\end{abstract}

anaesthesia; sedation; analgesia; thiopental.

\section{Introduction}

The use of different sedatives as preanaesthetic drugs in animals is today worldwide and has been adopted from human medicine. Within the latter discipline one of the most important reasons for such premedication is to moderate the patient's anxiety about the general anaesthesia and the following operation. This aspect is in most cases of no current interest in veterinary medicine and it is therefore important to consider the need for premedication prior to a general anaesthesia in each individual case.

One specific situation in veterinary medicine is when deep sedation has been produced for an examination (e.g. an X-ray) and the results indicate a need for general anaesthesia.
This unfortunate situation demands good knowledge of the sedative and its effects on the circulation and respiration.

The usefulness of medetomidine, an alphaadrenoreceptor agonist (Savola et al. 1986), as a sedative/analgesic for diagnostic and therapeutic procedures that do not require general anaesthesia is currently being studied by other investigators.

In the present study medetomidine was tested as a preanaesthetic drug in the dog. Dogs treated with physiological saline solution (placebo) or xylazine served as controls. Xylazine is known as a sedative in the dog and its cardiopulmonary effects have been studied (Klide et al. 1975). Xylazine is also used as a preanaesthetic drug and the 
amount of barbiturate needed to induce anaesthesia is then reduced (Walter 1985).

\section{Materials and methods}

\section{Animals}

The study comprised 25 healthy experimental beagles, 22 females and three males. The mean age of 23 of the 25 dogs was 11.8 months (range 8 to 20 months). Two dogs were excluded from the calculation of the mean age because of their high age, 6 and 9 years, respectively. The mean weight of the 25 dogs was $10.95 \mathrm{~kg}$, (range 8 to $14 \mathrm{~kg}$ ).

\section{Preparation of the dog}

After infiltration anaesthesia (lidocaine with adrenaline $1 \% 0^{1}$ ) in the awake dog, the left femoral artery was punctured and a teflon catheter was introduced into the aorta using the Seldinger technique (Seldinger 1953).

The length of the catheter was about $15 \mathrm{~cm}$ and its outer diameter was 1.05 or $1.25 \mathrm{~mm}$. In a few cases when the first arterial puncture failed, the right femoral artery was used instead of the left.

\section{Tested drugs}

The dogs were divided randomly into 5 groups with 5 dogs in each, wich were given the following treatment:

Group 1 Placebo - physiological saline - as a preanaesthetic drug, $2 \mathrm{ml} / \mathrm{dog}$ irrespective of body weight. Control group.

Group 2 Xylazine (Rompun ${ }^{\otimes 2}$ ) $2 \mathrm{mg} / \mathrm{kg}$. Control group.

Group 3 Medetomidine 3 , $10 \mu \mathrm{g} / \mathrm{kg}$.

Group 4 Medetomidine, $30 \mu \mathrm{g} / \mathrm{kg}$.

Group 5 Medetomidine, $60 \mu \mathrm{g} / \mathrm{kg}$.

1 Xylocain $^{\star}$ adrenalin $1 \%$ Astra, Södertälje, Sweden.

2 Rompun ${ }^{\oplus} 20$ mg/ml Bayer, Leverkusen, West Germany.

3 Medetomidine $1 \mathrm{mg} / \mathrm{ml}$ Farmos group, Turku, Finland.
The sedative, controldrug and placebo were administered intramuscularly (i.m.; M. triceps brachii) $20 \mathrm{~min}$ before induction of general anaesthesia.

Two dogs from each group (except for the xylazine group) were selected randomly for a separate test 2 weeks before the main test wich was performed identically except that atropine (Atropin ${ }^{84}$ ) $0.05 \mathrm{mg} / \mathrm{kg}$ was injected i.m. $10 \mathrm{~min}$ before the sedative (or placebo).

\section{General anaesthesia}

General anaesthesia was induced with $2.5 \%$ thiopental sodium (Pentothal ${ }^{\circledR}$ Natrium $^{5}$ ) given intravenously. After intubation the anaesthesia was maintained with halothane (Halothan ${ }^{(6)}$ ) and nitrous oxide mixed with $50 \%$ oxygen. The halothane concentration varied according to the individual reaction of each dog (variation 0-1\%). The flow of oxygen and nitrous oxide was maintained at $21 /$ min each.

\section{Schedule of the recording performed}

After the preparations described, the dog was placed in right lateral recumbency, and two recordings of the variables studied (see below) were made prior to the sedation and the atropine injection, respectively. If the dog was given atropine, 1 or 2 recordings were made 5 and/or $10 \mathrm{~min}$ after the atropine injection (before the injection of the sedative). A recording was made 10 and $20 \mathrm{~min}$ after the sedation. Further recordings were performed immediately after the thiopental injection and intubation and every $15 \mathrm{~min}$ during the $1 \mathrm{~h}$ general anaesthesia.

4 Atropin $^{\otimes} 0.5 \mathrm{mg} / \mathrm{ml}$ ACO, Solna, Sweden.

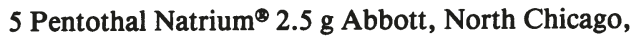
Illinois, USA.

6 Halothan $^{\oplus}$ Hoechst, Frankfurt (M), West Germany. 
Recordings at 15 min intervals were continued during the first hour of the post-anaesthetic period, and then 2, 3, 6 and $20 \mathrm{~h}$ after termination of the general anaesthesia. Finally, the dogs once again underwent a routine clinical examination, as prior to the test. The investigator tried to keep the anaesthesia deep enough for surgical procedures by following it in a conventional way with the help of the reflex pattern.

After the one-hour general anaesthesia, administration of the inhalation anaesthetic was ceased and the dogs were allowed to recover, breathing air.

\section{Variables recorded}

Objective recordings: ECG and blood pressure (systolic, mean and diastolic) were recorded on an ink-jet recorder (Mingograf 34, Siemens-Elema, Solna, Sweden). Lead II, CR was used to measure the heart rate and a pressure transducer (EMT 311, Siemens-Elema) recorded the blood pressure via the artery catheter. The blood pressure mentioned in the results is the mean blood pressure.

The respiratory rate was calculated by observing respiratory chest expansion.

Blood gas-analysis was performed on arterial blood samples drawn through the artery catheter. All blood samples were collected anaerobically into heparinized $2 \mathrm{ml}$ plastic syringes. The samples were analysed within 5 min after collection, using a standard electrode technique (ABL 3 Radiometer, Copenhagen, Denmark). Blood-gas values were corrected according to the rectal temperature.

Subjective recordings: Response to pain stimuli (pin prick sensation, reaction to pinch in the coronary border).

Degree of sedation (e.g. response to sound, ability to stand, calmness).
Depth of the general anaesthesia (reflexes and response to pain stimuli - see above). Colour of mucous membranes, capillary refill time, pulse quality and type of respiration.

\section{Results}

\section{Blood pressure}

Interindividual variations of the mean arterial blood pressure occurred in the groups receiving sedatives without prior atropine injection. In fact the dog with the lowest mean blood pressure value (after the sedation and during the general anaesthesia) belonged to the group premedicated with medetomidine $10 \mu \mathrm{g} / \mathrm{kg}$ (Fig. 1). In a few dogs the blood pressure was recorded continuously during the first $10 \mathrm{~min}$ of the sedation period. This check, however, did not give any further information.

In the sedated dogs premedicated with atropine (10 min prior to the injection of the sedative), the blood pressure rose markedly during the sedation period. The increase was most pronounced in the groups receiving medetomidine 10 and $60 \mu \mathrm{g} / \mathrm{kg}$. The mean values in these groups reached 175 and 210 $\mathrm{mmHg}$, respectively.

Fifteen minutes after the thiopental injection, the blood pressure in these atropine groups had dropped to the initial level (125$150 \mathrm{~mm} \mathrm{Hg}$ ) or were even lower. During the course of the general anaesthesia the pressure decreased slightly further.

The placebo dogs treated with atropine behaved differently. The blood pressure did not change considerably during the course of the test.

Note! The dogs in the xylazine group were not tested with atropine.

\section{Heart rate}

The heart rate and the blood pressure recordings showed an essentially similar pattern, 


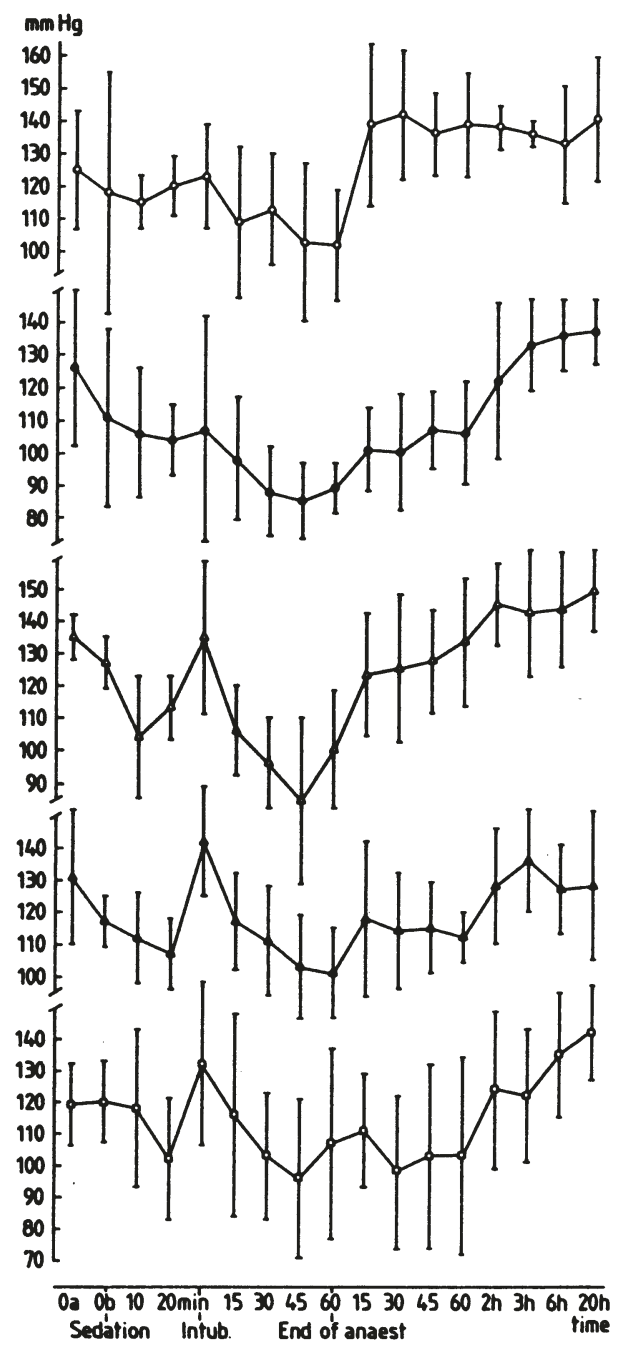

Figure 1. The mean arterial blood pressure in dogs given sedation prior to general anaesthesia. Five groups with 5 dogs in each. Mean value and standard deviation.

O Placebo

- Rompun

$\triangle$ Medetomidine $10 \mu \mathrm{g} / \mathrm{kg}$

- Medetomidine $30 \mu \mathrm{g} / \mathrm{kg}$

Medetomidine $60 \mu \mathrm{g} / \mathrm{kg}$
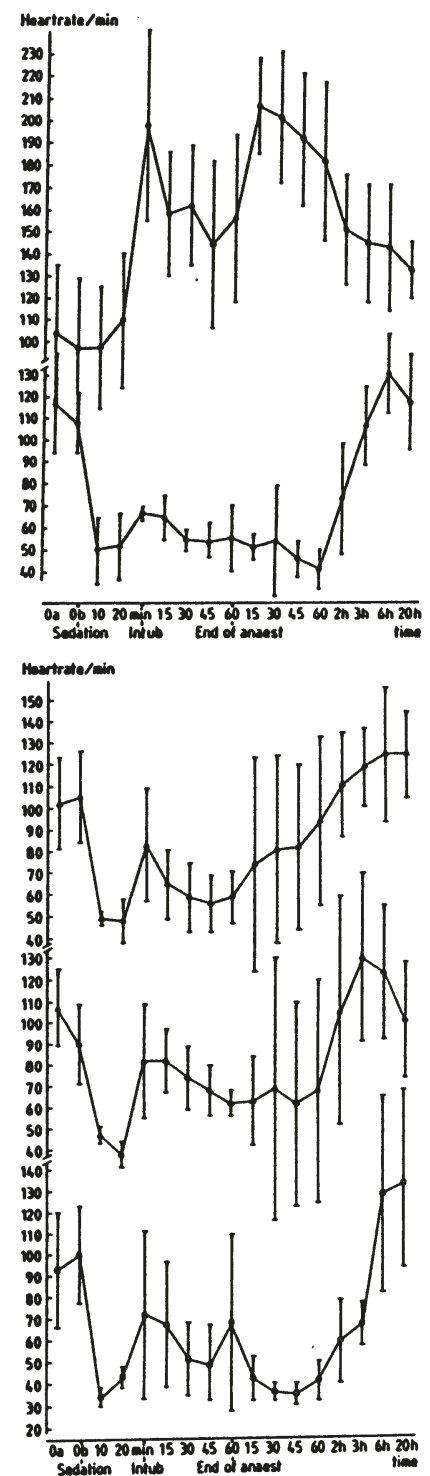

Figure 2 a-b. The heart rate in dogs given sedation prior to general anasthesia. Five groups with 5 dogs in each. Mean value and standard deviation.

O Placebo

- Rompun

$\triangle$ Medetomidine $10 \mu \mathrm{g} / \mathrm{kg}$

$\Delta$ Medetomidine $30 \mu \mathrm{g} / \mathrm{kg}$

$\square$ Medetomidine $60 \mu \mathrm{g} / \mathrm{kg}$ 
except in the placebo group (Figs. $2 a$ and 2b).

In 2 of the atropine-premedicated groups (medetomidine $60 \mu \mathrm{g} / \mathrm{kg}$ and placebo) the heart rate increased during the first $10 \mathrm{~min}$ after the atropine injection. In the other 2 groups (medetomidine 10 and $30 \mu \mathrm{g} / \mathrm{kg}$, respectively) the increase occurred within 10 min after administration of the sedative (i.e. $20 \mathrm{~min}$ after the atropine injection). Maximum values for all groups were reached 10 min after sedation, with the following mean values: placebo, 263 beats/min; medetomidine 10 and $60 \mu \mathrm{g} / \mathrm{kg}, 225 / \mathrm{min}$; and medetomidine $30 \mu \mathrm{g} / \mathrm{kg}, 146 / \mathrm{min}$. During the later part of the sedation, the heart rate started to drop in all groups given atropine (including the placebo group), and continued to decrease during anaesthesia, though less in the placebo group than in the others (placebo: about 150 beats/min; remaining groups: 80 $120 / \mathrm{min}$ ).

Post-anaesthetically the curves for the atropine and non-atropine groups showed the same appearance.

\section{ECG}

The ECG recordings did not differ between the groups. Nor did they diverge from other ECGs in generarl during this form of anaesthesia.

\section{Respiration}

During sedation the respiratory frequency decreased and the breathing became deeper (Fig. 3).

The respiratory rate in the atropine groups was similar to that in the groups not treated with atropine before sedation.

\section{Temperature}

The rectal temperature fell during general anaesthesia, but less markedly in the placebo and medetomidine $60 \mu \mathrm{g} / \mathrm{kg}$ groups. The

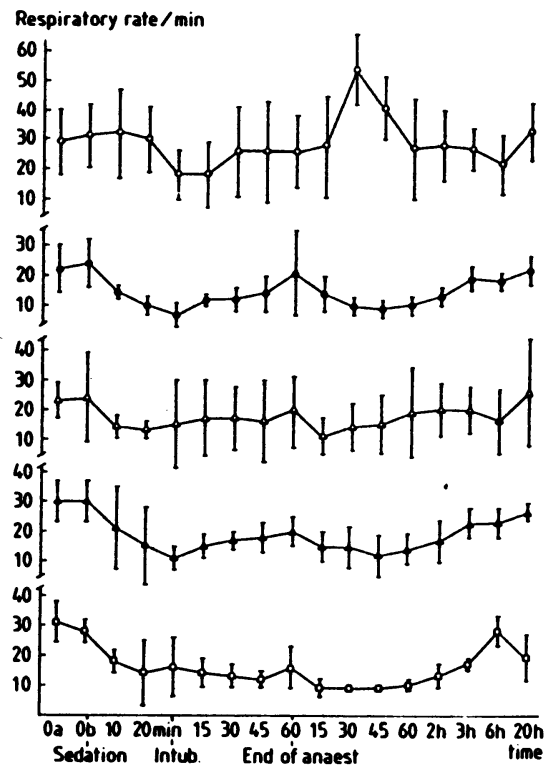

Figu re 3 . The respiratory rate in dogs given sedation prior to general anasthesia. Five groups with 5 dogs

in each. Mean value and standard deviation.

O Placebo

- Rompun

$\triangle$ Medetomidine $10 \mu \mathrm{g} / \mathrm{kg}$

$\triangle$ Medetomidine $30 \mu \mathrm{g} / \mathrm{kg}$ Medetomidine $60 \mu \mathrm{g} / \mathrm{kg}$

temperature in the placebo group regained the normal level about $1 \mathrm{~h}$ after the end of anaesthesia. In the other groups (including medetomidine $60 \mu \mathrm{g} / \mathrm{kg}$ ), a normal temperature was attained after 3-6 h.

\section{Blood-gas analysis}

$\mathrm{PaO}_{2}$ generally decreased slightly (in all groups) after administration of thiopental (from about $13 \mathrm{kPa}$ to $8-11 \mathrm{kPa}$ ) and then increased markedly during general anaesthesia (to 40-50 kPa).

Normal $\mathrm{PaO}_{2}$ values were reached within the first $15 \mathrm{~min}$ after the anaesthetic gas had been turned off.

$\mathrm{PaCO}_{2}$ rose temporarily after the induction 
of anaesthesia and the intubation (from about $5 \mathrm{kPa}$ to $5.5-7 \mathrm{kPa}$ ).

In all groups there was a slight decrease in base excess during anaesthesia (about 1-2 $\mathrm{mmol} / \mathrm{l})$. Irregular values were observed during the post-anaesthetic period in the groups premedicated with xylazine and medetomidine $60 \mu \mathrm{g} / \mathrm{kg}$.

\section{Sedation}

Dogs pretreated with atropine are not described separately.

The degree of sedation differed between the groups.

The placebo dogs were calm, but totally unsedated and their response to pain stimuli was the same as prior to the injections.

The dogs of the xylazine group were moderately to profoundly sedated after $10-20$ $\mathrm{min}$, and there was obvious pain depression, though not so strong as in the medetomidine 30 and $60 \mu \mathrm{g} / \mathrm{kg}$ groups. One of the xylazine-treated dogs started to wave her hed up and down about $10 \mathrm{~min}$ after the injection, and did not stop until thiopental was given. A second dog in this group developed a slight spasm in the limbs $5 \mathrm{~min}$ after the injection, and a third dog began to perform trot-like movements with the forelimbs 20 min after injection of the sedative (just prior to induction of the general anaesthesia).

The third group (medetomidine $10 \mu \mathrm{g} / \mathrm{kg}$ ) showed slight sedation $10 \mathrm{~min}$ after the injection and moderate sedation after about 20 min, except for $1 \mathrm{dog}$, which became very profoundly sedated - actually more than those receiving $60 \mu \mathrm{g} / \mathrm{kg}$. The pain depression in these dogs was slight, except in the profoundly sedated dog mentioned above (this dog also showed lower values of blood pressure, heart rate and respiratory rate than the others).
In the fourth group (medetomidine 30 $\mu \mathrm{g} / \mathrm{kg}$ ), the dogs displayed moderate to profound sedation after 3-5 min. The analgesia was moderate. In 3 of the dogs in this group ( 1 with atropine, 2 without), the mucous membranes appeared a little pale after sedation, compared with the colour prior to sedation.

The dogs of the last group (medetomidine 60 $\mu \mathrm{g} / \mathrm{kg}$ ) were profoundly sedated within 10 min after injection of the drug. One dog, however, was excited for 3-10 min after the injection, and 2 dogs showed a slight spasm in their limbs from time to time during the sedation period. In these dogs the mucous membranes were also slightly paler than prior to sedation. The dogs in this group exhibited very little response to painful stimuli. The profoundly sedated dogs were unable to stand, and did not react to loud sounds. In many of the sedated dogs (especially at higher dose levels) the nictitating membrane covered a considerable part of the eye. The reflexes of the moderately to profoundly sedated dogs were obviously reduced.

\section{Induction of anaesthesia}

In all the sedated groups a lower dose of thiopental sodium was needed for intubation compared with the placebo group (Table 1).

\section{Post-anaesthetic period}

The interval between the end of inhalation and the moment of extubation was shortest in the placebo group (mean value $6.75 \mathrm{~min}$ ) and longest in the group receiving medetomidine 30 and $60 \mu \mathrm{g} / \mathrm{kg}$ (18.1 and $17.5 \mathrm{~min}$, respectively). The other 2 groups were intermediate with respect to this interval $(8 \mathrm{~min}$ for xylazine and $12.5 \mathrm{~min}$ for medetomidine $10 \mu \mathrm{g} / \mathrm{kg}$ ). 
Table 1. Amount of thiopental needed for intubation in dogs given a sedative prior to general anaesthesia. Five groups with 5 dogs in each.

( $x=$ the most profoundly sedated dog in the whole study) ( $\delta$ = male dogs, the others were females)

\begin{tabular}{|c|c|c|c|c|c|c|}
\hline \multirow{2}{*}{$\frac{\text { Drug }}{\text { Placebo }}$} & \multicolumn{5}{|c|}{ Thiopental sodium $\mathrm{mg} / \mathrm{kg}$} & \multirow{2}{*}{$\frac{\bar{x}}{18.0}$} \\
\hline & $28.6 \delta$ & 18.2 & 17.2 & 13.5 & 13.1 & \\
\hline \multicolumn{7}{|l|}{ Xylazine } \\
\hline $2 \mathrm{mg} / \mathrm{kg}$ & 7.6 & 5.5 & 4.2 & 5.4 & $9.1 \delta$ & 6.4 \\
\hline \multicolumn{7}{|c|}{ Medetomidine } \\
\hline $10 \mu \mathrm{g} / \mathrm{kg}$ & 10.5 & 7.1 & $2.5^{x}$ & 8.3 & 7.6 & 7.2 \\
\hline \multicolumn{7}{|c|}{ Medetomidine } \\
\hline $30 \mu \mathrm{g} / \mathrm{kg}$ & 7.5 & 6.6 & 4.6 & 6.6 & 10.4 శ & 7.1 \\
\hline \multicolumn{7}{|c|}{ Medetomidine } \\
\hline $60 \mu \mathrm{g} / \mathrm{kg}$ & 5.7 & 3.4 & 3.2 & 8.3 & 5.7 & 5.2 \\
\hline
\end{tabular}

No dog showed excitation during the postanaesthetic period, but the unsedated dogs shivered during awakening (not longer than $1 \mathrm{~h}$ post-anaesthetically).

No vomiting was observed during the experiments, but on the other hand the dogs had not been fed for $12 \mathrm{~h}$ prior to the tests.

\section{Discussion}

Regarding the course of the general anaesthesia following sedation, there was no fundamental difference between the two drugs tested (medetomidine and xylazine). In comparison with the placebo group, there was constantly a higher degree of reflex depression, arterial hypotension, bradycardia and respiratory depression, and more prolonged awakening in the sedated dogs. The degree of these effects, however, was mainly dosedependent. The effects were less apparent and of shorter duration in the groups receiving medetomidine at the lowest dose level $(10 \mu \mathrm{g} / \mathrm{kg})$, but large individual variations occurred. In fact, the greatest hypotension during anaesthesia was noted in a dog premedicated with medetomidine at this lowest dose level.
The depth of the general anaesthesia was difficult to judge because of fluctuations in the degree of reflex depression during the course of the anaesthesia (this held for all groups except the placebo group). A consequence of this was an increased risk of apnoea when anaesthesia was induced with thiopental after sedation with the drugs investigated. On the other hand, a lower dose of thiopental was required after sedation of the dogs and this effect was dosedependent.

In the dogs which received atropine prior to sedation, the circulatory effects were reversed. Even during the course of the general anaesthesia and post-anaesthetic period, the dogs in the atropine groups showed a relatively higher blood pressure and heart rate.

On the basis of the above observations, the author would like to make the following recommendations for the use of medetomidine for premedication prior to general anaesthesia.

At a low dosage $(10 \mu \mathrm{g} / \mathrm{kg})$, the drug can be useful as a pre-anaesthetic drug, provided that the dogs are in a good general condition and that the anaesthesia is administered in an animal hospital or a clinic where the surgeons and their assistants are trained in managing unexpected apnoea. Even lower doses of medetomidine than the lowest one tested in the present study $(10 \mu \mathrm{g} / \mathrm{kg})$ ought to be tried for premedication purposes, since the sedative effect of the drug is very potent. Animals with a deteriorated general condition should not be premedicated at all, since the advantage of the lowered dose of thiopental does not necessarily balance the possible disadvantage of the negative effect of medetomidine (as well as of xylazine) on the circulation and respiration. It should be emphasized that thiopental used alone has a fairly moderae negative effect on the circulation and its obvious depressing effect on the respiration is easily controllable, in distinc- 
tion from the cardiovascular effects of the sedatives.

Atropine prior to sedation cannot be recommended on the basis of the present experience, as it is not known how the effect of atropine, with tachycardia and arterial hypertension, affects the risks of the anaesthesia.

\section{Acknowledgements}

This study was supported by grants from Farmos group, Turku, Finland.

The skilful assistance of Ann-Marie Lofgren and Pia Funkquist during the studies is greatly appreciated.

\section{References}

Klide A M, Calderwood H W, Soma L R: Cardiopulmonary Effects of Xylazine in Dogs. Amer. J. vet. Res. 1975, 36, 931-935.

Seldinger S I: Catheter replacement of the needle in percutaneous arteriography. Acta Radiol. 1953, 39, 368-376.

Savola JM, Ruskocho H, Puurunen J, Salonen J S, Körki $N$ T: Evidence for medetomidine as a selective and potent agonist at alpha ${ }_{2}$-adrenoreceptors. J. Auton. Pharmac. 1986, 5, 275-284.
Walter $H \mathrm{H}$ : Effects of atropine on xylazine-pentobarbital anaesthesia in dogs: Preliminary study. J. Amer. vet. Res. 1985, 46, 856-858.

\begin{abstract}
Sammenfattning
Effekt på blodcirkulation och respiration av ett nytt sedativum/analgetikum (medetomidin) som preanestetikum till hund.

Undersökningens syfte var att fastställa om medetomidin (Farmos group, Turku, Finland) kan användas till premedicinering inför allmän anestesi med tiopentalnatrium och halotan. Framför allt undersöktes medetomidinets cirkulatoriska och respiratoriska effekter. Hundar behandlade med xylazin (2 $\mathrm{mg} / \mathrm{kg}$ ) respektive placebo (fysiologisk koksaltlösning) användes som kontroller.

Medetomidin orsakade sänkning av blodtryck, hjärtfrekvens, och andningsfrekvens vid alla doseringar som testades. Dessa effekter var principiellt dosberoende, men det fanns stora individuella skillnader.

Medetomidin kan användas för premedicinering i den lägsta testade doseringen $(10 \mu \mathrm{g} / \mathrm{kg})$. Den sedativa effekten är emellertid så stark att en ännu lägre dos eventuellt skulle kunna vara tilräcklig för ändamålet.
\end{abstract}

(Received September 13, 1987).

Reprints may be requested from: Karin Bergström, Department of Surgery, Faculty of Veterinary Medicine, Swedish University of Agricultural Sciences, S-750 07 Uppsala, Sweden. 